\title{
Life Cycle Cost Management of Fixed Assets in Chinese Power Grid Enterprises
}

\author{
Yuanyuan Wang
}

\author{
School of economics and management, North China Electric Power University, Beijing 102200, China
}

Keywords: Power grid enterprise; fixed assets; life cycle; cost management

\begin{abstract}
Power grid enterprises are asset-intensive enterprises. At present, high life cycle cost of fixed assets is an important factor that restricts the fixed assets' efficiency and economic growth of power grid enterprises. The characteristics of fixed assets in grid enterprises bring many difficulties to the management of fixed assets in grid enterprises. The traditional cost management mode of fixed assets is difficult to adapt to the needs of new forms of operation and management. Based on the status of cost management and existing problems of cost management in Chinese power grid enterprises, combining with the internal and external factors such as the characteristics of power grid enterprises, this paper analyzes the reasons why the cost of fixed assets in the whole cycle is difficult to control and introduces the concept of whole life cycle cost management of fixed assets. Suggestions on cost management of fixed assets in power grid enterprises are put forward.
\end{abstract}

\section{Introduction}

Fixed assets of power grid enterprises are characterized by large quantity, scattered distribution and difficult management. The application of life cycle cost management thought and mode to fixed assets' management of power grid enterprises can solve various problems in traditional fixed assets' cost management, optimize the cost-effectiveness of fixed assets, and promote power grid enterprises' better development. Therefore, the power grid enterprises must pay more attention to the whole life cycle cost management of fixed assets. This paper is concerned with the whole life cycle cost management.

\section{Analysis of Fixed Assets and Their Costs of Grid Enterprises}

\subsection{Definition and characteristics}

According to the accounting system, fixed assets refer to tangible assets held for the purpose of producing commodities, providing labor services or leasing, which are of high value and have a service life of more than one year. Fixed assets are indispensable means of labor in the line operation of power grid enterprises. From the perspective of physical objects, the fixed assets of power grid enterprises mainly include transmission lines, substation equipment, distribution lines and equipment, electricity metering equipment, automatic control equipment and so on[1].

From the perspective of these fixed assets owned by grid enterprises, the fixed assets of grid enterprises have the following three characteristics. Firstly, the quantity and variety is much. The value of fixed assets accounts for about $70 \%$ of the total assets of grid enterprises. Secondly, distributed throughout the country, the transmission network spans different geographical and climatic conditions, bringing management difficulties. Thirdly, the investment is big. The price of general electric equipment can reach tens of thousands Yuan; some may even reach tens of millions Yuan. In particular, the technology of power grid construction and transformation has been constantly updated in recent years. As a result, the fixed assets of power grid enterprises are renewed quickly and changed frequently, and more manpower, material and financial resources are needed.

\subsection{Definition of total life cycle cost of fixed assets}

The life cycle of fixed assets is the life cycle covering the planning, investigation, purchasing, acceptance, using, maintenance, scrapping and treatment of assets. In simple terms, the life cycle of fixed assets can be divided into three cycles: input period, operation period and retirement period. Correspondingly, the total 
life cycle cost of fixed assets can also be roughly divided into the costs of three stages, namely input period cost, operation period cost and retirement period cost[2].

\subsubsection{Input period cost}

Input period cost refers to the capital input, which is divided into planning period cost, construction period cost and follow-up investment. Planning period cost and construction period cost are collectively referred to as initial input; Follow-up input refers to the technical transformation input implemented in the life cycle of fixed assets, both of which are reflected by the original value of fixed assets.

\subsubsection{Operating period cost}

The operating period cost refers to the cost related to operation and maintenance during the operation of assets. The cost composition is classified according to the type of operation, which can be divided into operation cost, repairing cost and cost of failure. The operating costs are classified into direct costs and indirect costs according to the type of activity. Direct costs consist of labor, materials, tools and outsourcing costs. Outsourcing cost refers to the cost paid by an enterprise to an external company for carrying out part of operation and maintenance. Indirect cost refers to the indirect cost associated with the operation of cost objects or refers to costs that are directly related but cannot be traced to specific objects in an economically reasonable way.

\subsubsection{Retirement period costs}

The cost of retirement period of fixed assets refers to the costs related to the disposal of assets, including disposal costs and clean-up costs.

\section{The Importance of Cost Management of Fixed Assets}

\subsection{Grid enterprises urgently need to improve the cost-effectiveness of their fixed assets and achieve more long-term development}

In traditional management of fixed assets in grid enterprises, enterprises need to spend a lot of capital and technology, resulting in increased management costs. The high cost and limited efficiency of fixed assets are very unfavorable to economic benefits and long-term development of enterprises. Therefore, it is required that grid enterprises should strengthen the cost management of fixed assets and improve the management efficiency and economic benefits of grid enterprises.

\subsection{National policies and reform of electricity price raise higher requirements for cost management of fixed assets in grid enterprises}

Power grid enterprises are asset-intensive enterprises that concern the national economy and people's livelihood. With the rapid development of national economy, the fixed assets' investment maintained a rapid growth during the "11th five-year plan" and "12th five-year plan". The investment in the 13th five-year plan will maintain a medium-high speed of growth[3]. The further reform of electricity transmission and distribution has also put forward higher requirements for the operation of fixed assets in grid enterprises, which makes the cost management of fixed assets in grid enterprises become particularly important.

\section{Problems in Cost Management of Fixed Assets in Power Grid Enterprises}

\subsection{The origin of cost management is ignored}

Planning, designing and procurement in the input period is the source of the total life cycle management of fixed assets. However, in fact, the initial input cost of grid assets such as planning, designing and construction is not paid attention to, which will have adverse effects on subsequent depreciation and other activities of grid enterprises. In general, provincial companies are responsible for the approval of fixed assets and construction projects. However, due to the cumbersome process of approval, it is easy not to match the demand time of power grid enterprises at the municipal level. Municipal power grid enterprises first sign the agreement of "use first, pay later" with suppliers, so it is very easy to purchase fixed assets in advance. In fact, this behavior indicates the confirmation agreement for equipment suppliers in advance. It is also easy to increase the risk of fraud between procurement personnel and equipment suppliers, and it is not conducive to 
the cost control at the source of fixed assets. More importantly, this action has a negative impact on the recognition and measurement of fixed assets and will hinder the subsequent accounting treatment of fixed assets.

\subsection{The nature of fixed assets' operating expenses is unclear}

The operation and maintenance expenses of the fixed assets will inevitably occur during the subsequent operation. These expenses can be roughly divided into two situations: one is repairing expenses, which are directly recorded into current expenses in the accounting treatment; The other kind belongs to the improvement expenditure of assets, which specifically refers to the expenditure that can extend the service life of the fixed asset or make its quality get substantial improvement or is expected to bring more economic benefits to the enterprises[4]. The book value of the fixed asset should be included in the accounting treatment and be apportioned on schedule. But in practical work, in order to solve the difficulty of actual work application and financial difficulties, also for simple accounting treatment, part of the grassroots units tend to confuse the boundaries of cost expenditure and capital expenditure, which will result in inaccurate accounting measurement, impacting assessment of the cost of the fixed assets' management, also forming off-balance-sheet assets at the same time, creating accounts disagreeing with physical inventory of fixed assets, which makes ineffective cost management of fixed assets.

\subsection{Traditional modular management mode of fixed assets can lead to unclear responsibilities.}

Most of the power grid enterprises are still running the traditional modular management mode, isolating engineering, operation, maintenance and other aspects to meet the needs of the business, lacking overall planning and control. The staff of each link often only pays attention to the cost control's goal and management effect at this stage. However, it's not enough to the total cost of fixed assets. Resulting work cohesion is not tight and each stage of inspection standard is not unified and the cost management of each stage is individual. Each link of cost information is unable to achieve effective sharing. Therefore, it is difficult to optimize the total cost of fixed assets management, which will adversely affect the economic efficiency of fixed assets and the sustainable development of power grid enterprises.

\section{Reasons Why the Fixed Assets Cost of Grid Enterprises is Difficult to Manage}

\subsection{Fixed assets are complex in cost management and require high professional level}

Fixed assets of power grid enterprises have many links and levels in management, involving different categories such as production, agricultural network, marketing, information, logistics and so on. They are highly professional and require inter-disciplinary talents who know accounting knowledge and understand engineering projects to carry out effective cost management [5]. For a long time, due to the limitations of philosophy, manpower, technology and the lack of simplified and practical asset classification, these have brought great inconvenience to the cost management of fixed assets.

\subsection{Lack of corresponding and reasonable assessment mechanism in grid enterprises}

In recent years, with the application of ERP system, many operational regulations and business processes have been introduced successively, but the corresponding assessment mechanism has not been improved, and there is no clear division of responsibilities for the cost management of fixed assets in different stages. The lack of consistency in job responsibilities, daily maintenance, performance evaluation and other aspects leads to the cost management personnel at all stages of fixed assets focusing only on the cost management objectives and performance evaluation at this stage while ignoring the ultimate goal of minimizing life cycle cost. At the same time, the power grid enterprise has the phenomenon of passive management of fixed assets by business departments, insufficient personnel for fixed asset cost management and unclear responsibilities for cost management. These management omissions cause great inconvenience to the cost management of fixed assets.

\subsection{Lack of guidance on cost management of fixed assets at the policy level}

The cost management of fixed assets in power grid enterprises lacks corresponding guidelines. In the absence of criteria for how to accurately confirm and measure the fixed assets, and without a clear definition 
of the cost's capitalization or expenditure during the follow up period, the life cycle cost management of fixed assets in power grid enterprises must be non-standard and inaccurate.

After analyzing the root cause of the problems existing in the cost management, the main suggestion we give for the cost management of fixed assets in grid enterprises is to appoint the life cycle cost management method. The life-cycle cost management method of fixed assets is a great change to the original traditional cost management method of fixed assets, which is innovative.

\section{The Detailed Explanation of the Life Cycle Cost Management Method of Fixed Assets}

\subsection{Definition}

Life cycle cost management of fixed assets is a cost management method which aims at maximizing the overall benefit of fixed assets and pursuing the minimum life cycle cost of fixed assets on the premise of satisfying safety and efficiency.

\subsection{Measures}

6.2.1 Confirm the accounting value of fixed assets accurately during the investment period

The main source of fixed assets in grid enterprises is the transfer of completed projects. Accurate, timely and complete project accounting in capital transfer is a good start to achieve efficient cost management of fixed assets. First of all, we should start with the final accounting report of the completion of the project, standardize the preparation of the final accounts of the project's completion, strictly inspect the projects that do not belong to fixed assets, and the value of ancillary equipment should be amortized to the value of the corresponding equipment. The second is to speed up the preparation examination and approval progress of the final report on project completion, shorten the time for temporary estimation of fixed assets into the account, reduce the total amount of temporary estimation of fixed assets, and accurately reflect the actual transfer price of the project under construction into fixed assets. The third is to strengthen the training of personnel related to project's final accounts and cost management, improve the compilation level of project's final accounts, and promote the interconnection between financial knowledge and business knowledge.

6.2.2 Accurate accounting and attribution

The depreciation expense of fixed assets is an important part of the cost accounting in operation period. The choice of depreciation policy for fixed assets is at the level of provincial power grid enterprises. Provincial grid enterprises need to take the characteristics of the fixed assets into full consideration, and combine the current financial system and tax law to give the subordinate grid enterprises some space for fixed assets' depreciation, and choose a more reasonable fixed assets' depreciation method [6]. Secondly, the capitalization and expense disbursement of follow-up operation and maintenance expenses should be defined clearly. For those improvement expenditures that can extend the service life of fixed assets or substantially improve their quality, they should be capitalized and accounted into the book value of fixed assets. For general repairs, the cost will be directly charged.

6.2.3 Refine responsibilities and strengthen the construction of performance evaluation system

Standardize the management procedures of each part, refine the responsibility of the cost management of fixed assets and write it directly into the responsibilities of departments and employees, implement the responsible departments and responsible persons in accordance with the principle of "who is responsible for whose use" and follow up the management of fixed assets in all stages, fully understand and master the points of fixed assets' distribution, usage and quality. The cost management is directly linked to the performance evaluation of leading cadres, and the cost management is established by keeping systematic and consistent in the aspects of post responsibility, daily maintenance and performance evaluation. Establish the reward and punishment system of fixed assets' cost management to ensure the efficient operation. To strengthen the communication and coordination of information of all stages to ensure the common goal of personnel at all stages is to minimize the cost of the whole cycle under the premise of ensuring the reliable and safe operation of the fixed assets rather than just focusing on the cost management at one stage. 


\section{Conclusion}

The sustainable and healthy development of power grid enterprises needs to take the reliability and security of fixed assets as the premise. And at the same time, enterprises should rationally use the life cycle cost management method of fixed assets, aiming at the lowest total cycle cost. Finally, under the premise of guaranteeing the scientific and effective operation of fixed assets, it can improve the efficiency of the use of assets, reduce the cost and expenditure of enterprises, and create greater economic and social benefits.

\section{References}

[1]. Chen Fachen, Study on the Total Life Cycle Management of Fixed Assets of A Power Grid Company, 2013.

[2]. Huang Wei, Preliminary Study on the Life Cycle Cost Management of Fixed Assets: Guizhou Electric Power Technology, 2014.

[3]. Zhang Xiaolong, Discussion on the Total Life Cycle Management of Fixed Assets of Grid Corporation: Research on Modern State-owned Enterprises, 2016.

[4]. Cai Runsheng, Discussion on Improving the Management of Fixed Assets in Power Grid Enterprises: Science and wealth, 2016.

[5]. Hou Feng, Discussion on Problems and Improvement Measures of Fixed Assets Management in Power Grid Enterprises: Modern Economic Information, 2015.

[6]. Sun Boliang, Brief Analysis of the Current Situation and Improvement Measures of Fixed Assets Management in Power Enterprises, 2013. 